in vivo $34: 2325-2336(2020)$

doi:10.21873/invivo.12045

\title{
Ablation Precision and Thermal Effects of a Picosecond Infrared Laser (PIRL) on Roots of Human Teeth: A Pilot Study Ex Vivo
}

\author{
REINHARD E. FRIEDRICH ${ }^{1 *}$, MARIA QUADE ${ }^{1 *}$, NATE JOWETT ${ }^{2,3,4}$, PETER KROETZ $^{4}$, \\ MICHAEL AMLING ${ }^{5}$, FELIX K. KOHLRUSCH ${ }^{1}$, JOZEF ZUSTIN ${ }^{5,6}$, \\ MARTIN GOSAU ${ }^{1}$, HARTMUT SCHLÜTER ${ }^{7}$ and R. J. DWAYNE MILLER ${ }^{4,8,9}$ \\ ${ }^{1}$ Oral and Craniomaxillofacial Surgery, Eppendorf University Hospital, \\ University of Hamburg, Hamburg, Germany; \\ ${ }^{2}$ Otorhinolaryngology, Eppendorf University Hospital, University of Hamburg, Hamburg, Germany; \\ ${ }^{3}$ Otolaryngology - Head and Neck Surgery, Mass Eye \& Ear and Harvard Medical School, Boston, MA, U.S.A.; \\ ${ }^{4}$ Atomically Resolved Dynamics Division, Max Planck Research Department for Structural Dynamics, \\ University of Hamburg, Hamburg, Germany; \\ ${ }^{5}$ Institute of Osteology and Biomechanics, Eppendorf University Hospital, \\ University of Hamburg, Hamburg, Germany; \\ ${ }^{6}$ Institute of Pathology, Gemeinschaftspraxis Pathologie-Regensburg, Regensburg, Germany; \\ ${ }^{7}$ Institute of Clinical Chemistry and Laboratory Medicine, \\ Eppendorf University Hospital, University of Hamburg, Hamburg, Germany; \\ ${ }^{8}$ Departments of Chemistry and Physics, University of Toronto, Toronto, Canada; \\ ${ }^{9}$ PIRL Laboratory, Eppendorf University Hospital, University of Hamburg, Hamburg, Germany
}

\begin{abstract}
Background/Aim: Picosecond infrared laser (PIRL) was investigated regarding its possible therapeutic application in cutting dental roots. Materials and Methods: Extracted human teeth were processed in the root area by laser ablations followed by histological evaluation. Dentin adjacent to the cutting surface was evaluated morphometrically. Results: PIRL produced clearly defined cutting boundaries in dental roots. At the bottom of the cavity, the ablation surface became slightly concave. Heat development in this scantly hydrated tissue was considerable. We attributed the excess heating effects to heat accumulation due to multiple pulse overlap across a limited scan range imposed by tooth geometries. Conclusion: Defined areas of the tooth root may be treated using the PIRL. For clinical translation, it would be necessary to improve beam
\end{abstract}

This article is freely accessible online.

*These Authors contributed equally to this study.

Correspondence to: Reinhard E. Friedrich, MD, DMD, Ph.D., FEBOMS, Eppendorf University Hospital, University of Hamburg, Martinist. 52, D-20246 Hamburg, Germany. Tel: +49 40741053259, e-mail: rfriedrich@uke.de

Key Words: Picosecond infrared laser, apicoectomy, oral surgery, thermal effects, laser ablation. delivery to facilitate beam steering for the intended oral application (e.g. by using a fiber) and identify optimal repetition rates/scan speeds combined with cooling techniques to minimize accumulated heat within ablation cavities.

Precise processing of hard tissues is a daily task of dentists and oral and maxillofacial surgeons. The application of lasers has led to technical improvements in certain fields of dentistry and surgery (1-5). Further developments in laser technology paved the way to devices allowing selective energy-transmission to pass down to subcellular structures (6-13). A prototype pico-second infrared laser (PIRL) already has provided evidence for successful targeted, athermal and organ-preserving tissue removal in the head and neck area (14-18). Recommended laser applications for the treatment of diseases of the oropharyngeal regions are predominantly soft tissue lesions (19-22) and restorative treatment of certain dental hard tissues (23). Laser application for the separation of hard tissues and structures such as bones or teeth has remained largely experimental (7, 15, 24-28). However, lasers are in clear competition with conventional drills in these applications, with the use of the latter being faster and more cost-effective $(4,7,29-33)$. In oral surgery, amputation of an inflamed tooth root is a well-established intervention to preserve the function and aesthetics of a non-vital tooth. However, the long-term success of this procedure is tenuous 
(34). A tissue-sparing and largely atraumatic removal of the root tip may increase the rate of tooth preservation. PIRL ablation is dependent on superheating of water in a target volume $(8,35)$. Though dental tissue has relatively low water content, the impulsive forces generated by PIRL acting on the heterogeneous location of water in teeth may be sufficient for athermal ablation (7). The performance of PIRL in ablation of various dental structures and optimal beam delivery parameters to minimize excess thermal energy deposition remains unknown. The ablative properties of PIRL were therefore tested under experimental conditions with special consideration on the thermal effects during procedures. Earlier experience with the use of PIRL in the surface treatment of teeth was used for designing the experimental approach (7).

\section{Materials and Methods}

Picosecond infrared laser (PIRL). The experiments were carried out in the laser laboratory at the University Hospital HamburgEppendorf. The PIRL (Attodyne Inc, Toronto, Canada) used for the experiments is a prototype assembled by Miller and co-workers (7). PIRL was used for serial incision of dental roots. Certain requirements of the laser-beam scanning system were made in this application. The experimental system must provide conditions allowing a stable linear incision of hard and curved tissue. The device should enable precise and small cuts into the specimen considering the root anatomy, in particular the very limited amount of root available for ablation to preserve tooth retention in the alveolus. Other considerations are the clinical requirements for the treatment outcome, specifically the requirement of selective dentin ablation while sparing tissue outside of the focal volume. The PIRL system used in these studies did not have an autofocus beam delivery system. In the current setting, the PIRL output beam was manually focused to a tight spot to achieve optimal photon density for ablation. Therefore, manual adjustment of the output beam during the ablation procedure was mandatory. Owing to the fixed focal length of the experimental laser setup, initial cuts herein were made stepwise by adjusting the distance between the sample and objective lens until a consistent depth of ablation was achieved across the focal plane. The running pattern of the PIRL over a certain area is z-shaped. The main beam and pulse characteristics of the laser output are summarized in Table I.

Human teeth. All teeth were removed during extractions or osteotomies, immediately stored in formalin filled transport boxes and numbered in chronological order. All teeth were completely preserved in their root area. In all cases, after informing patients about the study objective, the teeth were voluntarily given to the practitioner (REF) for further investigations. The examinations were approved by the institutional review board of the university hospital as a prerequisite for a medical dissertation in dentistry (MQ). These investigations were conducted in accordance with the Hamburgisches Gesundheitsdienstgesetz (Hamburg Health Service Act) and do not require approval by an ethics committee.

Experimental set-up. First, a suitable tooth was selected for the respective experiment. Care was taken to ensure that the surfaces to be ablated were as flat as possible and without strong curvatures in order to achieve the most uniform result possible (36). The requirement would be unnecessary with an autofocus. The respective tooth was removed from the transport box with protective gloves, cleaned with distilled water, and fixed with orthodontic wax on a metallic plate below the laser window. A further wax strip was placed over the tooth outside the laser area to protect the item from involuntary movement during procedures. The metallic holder was firmly screwed onto the worktable. The tested root surface was aligned as horizontally as possible with respect to the laser source. With three alignment laser beams derived by beam-splitting of a low-energy helium-neon laser and a height adjustable table, the focus point of the laser on the object was individually adjusted. The object was in focus when all three alignment laser beams met in one point on the target's surface.

The course of the laser was aligned perpendicular to the long axis of the root and approximately parallel to the root surface. In order to test the ablation performance of the laser, several parallel running paths were traversed on a single tooth, starting in the region close to the apex. In these teeth either the total number of scans or the energy output was varied from ablation distance to ablation distance. The orientation beam enabled the safe focusing of the working beam for the running track (approx. $2 \mathrm{~mm} \times 3 \mathrm{~mm}$ ). In every experiment, a bowl of distilled water and a cotton swab were provided so that the tooth could be moistened manually prior to each ablation procedure. It should be noted here that this thin layer of water is rapidly depleted in both transporting excess heat and ablation by intervening interactions between PIRL and the tooth.

In these experiments, incisions were made only in the tooth root without complete amputation of the apex. This procedure was chosen in order to unequivocally assess the entire ablation down to the preparation base in one tissue section. Each tooth was scanned at the root area by PIRL 5 to 20 times. In these teeth the focus was readjusted during laser application because of the increasing depth of the tooth cut and the narrow application gap. Two teeth of the series were analyzed during the test by a thermal imaging camera to record heat generation on the surface of the scanning field. All procedures on the object were registered via cameras and stored electronically.

Thermal imaging camera. Temperature changes during laser ablation of dental roots was recorded with a thermal imaging camera (InfraTec PIR uc 180, InfraTec, Dresden, Germany) using IRBIS 3plus software (InfraTec). The thermal imaging camera recorded a temperature reading every millisecond. The camera was used to measure the temperature at the ablation point during the laser procedure. First, a point on the tooth surface was chosen that was not ablated by the laser to determine the basic temperature of the tooth. Then the measuring point in the ablation zone was selected for temperature measurement during the ablation process. Each ablation scan was separately digitally recorded and the temperature values were displayed in a diagram.

Documentation and evaluation. All cuts were visually evaluated in every phase of the preparation process with regard to the appearance of the cut (smooth, step-like, irregular), the cutting bottom condition (flat, blasting), and color changes in the root surface or superficial root layers. After completion of experiments, photo documentation of every single laser-treated tooth was made (Scando dyn A+ color, Kaiser Fototechnik, Buchen, Germany). Furthermore, images of the 
Friedrich et al: PIRL and Root Resection of Teeth

Table I. Technical characteristics of PIRL for the treatment of human tooth roots.

\begin{tabular}{|c|c|c|c|c|c|c|c|}
\hline & Wavelength $(\lambda)$ & $\begin{array}{c}\text { Pulse } \\
\text { energy (EP) }\end{array}$ & $\begin{array}{c}\text { Beam } \\
\text { diameter }(\mathrm{dL})\end{array}$ & $\begin{array}{c}\text { Average } \\
\text { irradiance (@) }\end{array}$ & $\begin{array}{l}\text { Ablation time } \\
\text { per trial (Ts) }\end{array}$ & $\begin{array}{c}\text { Pulse } \\
\text { spacing (Tp) }\end{array}$ & $\begin{array}{c}\text { Power on focal } \\
\text { point (PB) }\end{array}$ \\
\hline PIRL & $2.94 \mu \mathrm{m}$ & $0.276 \mathrm{~mJ}$ & $200 \mu \mathrm{m}$ & $13.7 \mathrm{~W} / \mathrm{cm}^{2}$ & $0.204-1.600 \mathrm{~s}$ & $60-100 \mu \mathrm{m}$ & $335-470 \mathrm{~mW}$ \\
\hline
\end{tabular}

laser cuts were taken using a 3D laser scanning microscope (LEXT, Olympus Deutschland GmbH, Hamburg, Germany) and a stereo microscope (SZH10, Olympus).

Histology. Teeth were cut with a diamond saw (Exakt Advanced Technologies GmbH, Norderstedt, Germany) in the longitudinal axis direction of the tooth. This cutting direction allowed the measurement of the entire depth of the laser cut. The transected tooth was processed for histological staining (37). One half of a tooth was placed in snap cap glass with the cut surface facing down. Then the cavity was carefully filled with the casting solution $(1000 \mathrm{ml}$ methylmetacrylate (MMA), $6.6 \mathrm{~g}$ benzoyl peroxide (BPO), $100 \mathrm{ml}$ nonylphenol). Shortly before filling, the starter fluid (N,N dimethylp-toluidine, $250 \mathrm{ml}$, Merck 8.00590, Merck, Darmstadt, Germany) was added to the casting solution. Afterwards, identification labels marked with pencil were put into the glasses, sealed air tightly with lids and placed in a water bath (Temperature $4^{\circ} \mathrm{C}$ ) for further processing. These steps were carried out under the laboratory air vent. The liquid cured overnight at $4{ }^{\circ} \mathrm{C}$ in a water bath. The next day, the cured blocks were beaten out of the glass under the air vent and cleaned from glass remains. Excess acrylate of the blocks was removed. Blocks were fixed on the microtome and sections with a thickness of 3-5 $\mu \mathrm{m}$ were taken. Sections were placed on previously processed slides (coated with gelatin) using a brush and moistened with stretching liquid ( $80 \%$ isopropanol). Blisters and wrinkles were removed from the section with another brush. Then, the object was covered with a polyethylene (PE) foil, fixed by pressing and stored overnight in a drying cabinet at $60^{\circ} \mathrm{C}$. Subsequently, the PE foils of the slides were removed, and the slides were processed for the Masson-Goldner trichrome dyeing. This staining method specifically stains connective tissue and is particularly suitable for staining bone and dental tissue. The mineralized matrix is colored green, nonmineralized tissue such as cytoplasm is colored red. Artificial mineralization defects, e.g. caused by thermal effects, turned out to be grayish pale in this dyeing method (38).

Each stained specimen was examined under a microscope (Axiophot 2, Carl Zeiss Microscopy, Jena, Germany), microphotographed, and regions of interest were measured using ZEN software (Zeiss Efficient Navigation, Carl Zeiss). Light gray areas in the colored histological sections were interpreted as thermal impact on dentin. Suspected thermal damage to the cutting bottom was quantitatively measured with a line grid provided by ZEN. Prior to actual measurements, a test measurement was carried out with a test specimen to ensure the accuracy of the evaluation. Up to fifteen measurements were taken per laser cut. A further image of the measured distances defined on each histological section was recorded in order to store the measurement data of the image. For some sections, the measurement area was not extended enough to perform 15 individual measurements. In these cases, the calculation was based on the dentin area usable for measurement. Samples 2.2 and 7.1 were also analyzed using a scanning electron microscope (SEM).
Statistics. Kruskal-Wallis test was used to determine differences of thermal impact on dentin with respect to number of scan applications and ablation depths. The limit of statistically significant values was set at $p<0.05$.

\section{Results}

The osteotomies could be performed without problems and exactly in the preselected focal length. Re-focusing of the control laser became a challenging process during the procedures.

Visual and microscopic findings. Without optical magnification, various properties of the laser cuts attracted attention, for example rectangular, sharp edged cuts (Figure 1). Two out of a total of 55 laser cuts in the dentin showed traces of burns visible without magnification (Figure 1C). One of these cuts was made by 10 scans without refocusing the laser beam and the other was performed with manual refocusing without visible light beam bundling as a focusing aid. Both preliminary tests were performed to optimize scanning/focus parameters and excluded from statistical analysis. With a slight magnification, grooved structures became visible on the laser cutting bottom (Figure 1A and B). At higher magnification, the ripple of the cutting bottom was more pronounced (Figure 1B). Two slides were examined in the LEXT microscope (tooth No. 2.2, section 4 and tooth No. 7.2, section 1). At the cutting edge of tooth No. 2.2 (Figure 1D) the edge was visible as a relatively smooth line and the cutting base was even. With a $1 \mathrm{x}$ zoom, jagged margins were visible on tooth No. 7.2 (Figure 1E). The rippled incisal base was also still visible, as well as some small dark holes showing the opened dentin tubules. With $4 \mathrm{x}$ zoom, the cutting ground was rugged in a hilly fashion. No corrugated structures were visible (Figure 1F). Different depths of incisions were observed. These were partly wavy, smooth or oval to rounded at the bottom of the cut surface. The deeper the incision, the more rounded or converging were the cutting edges at the base of the ablation surface (Figure $1 \mathrm{G}$ and $\mathrm{H}$ ). Focally, sections of the bottom of the laser cut appeared non-uniform. At higher magnifications, a corrugated bottom was visible under the light microscope with an irregular surface and partly altered dyeability of the matrix of the cementum became apparent (Figure 1G). Some of the chipped dentin layers covered the cut base. The conical cutting edge was conspicuous in all sections. Gray areas in the marginal dentin were detected 
A

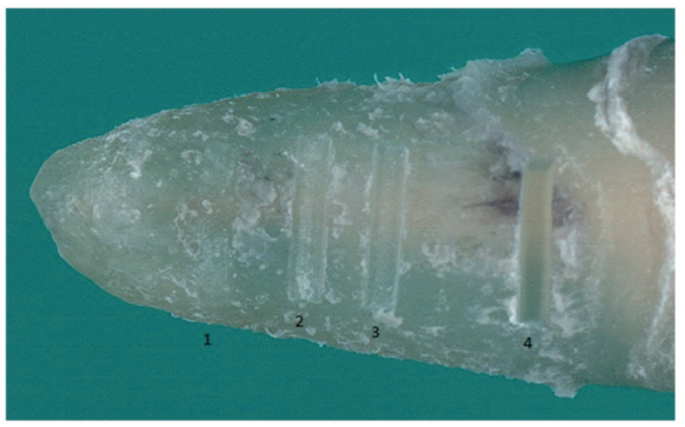

C

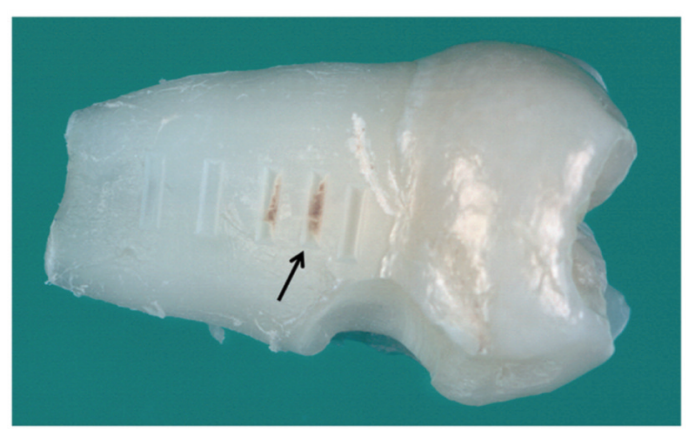

E

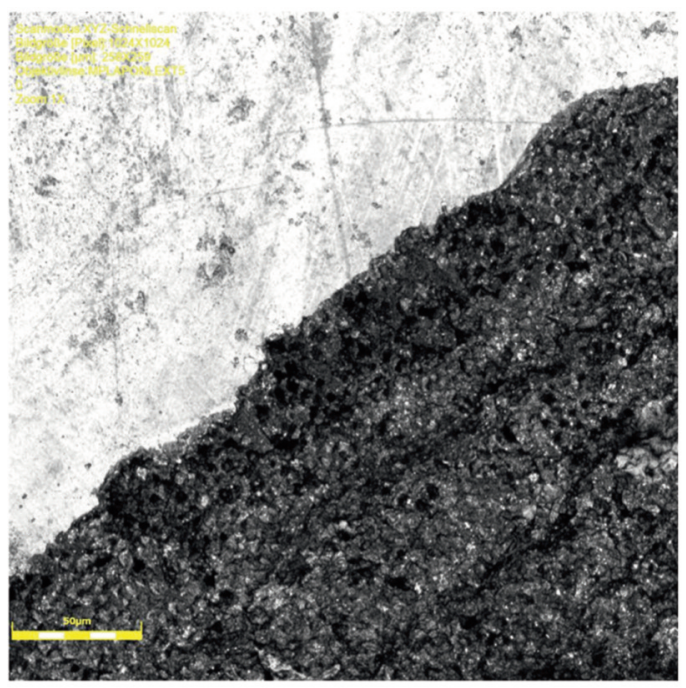

G

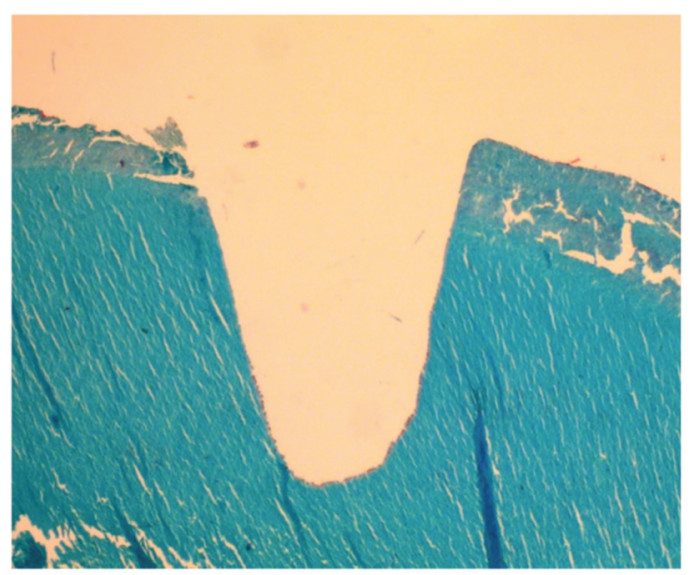

B

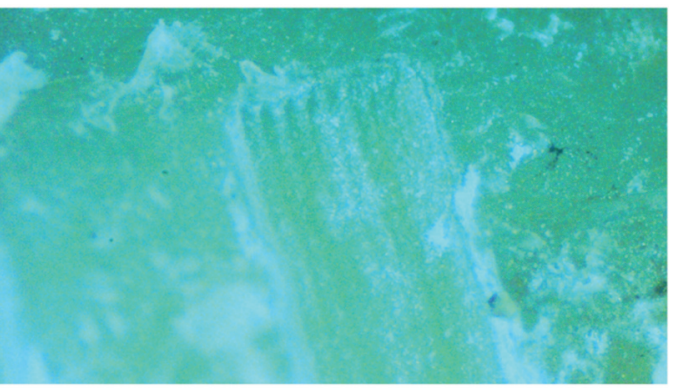

D
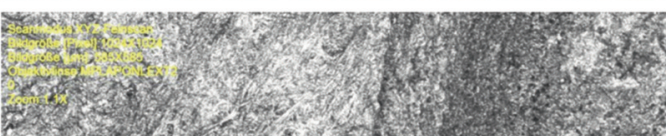

7.

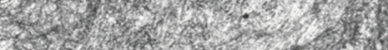

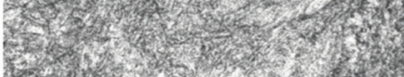

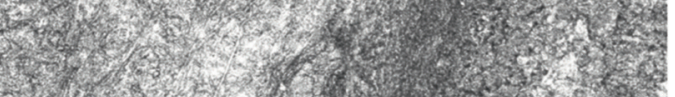

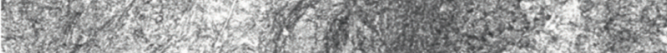

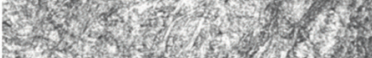

2.1.

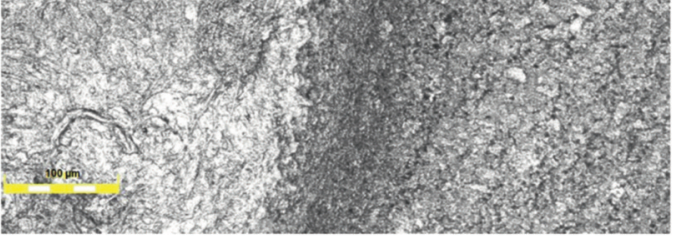

$\mathbf{F}$

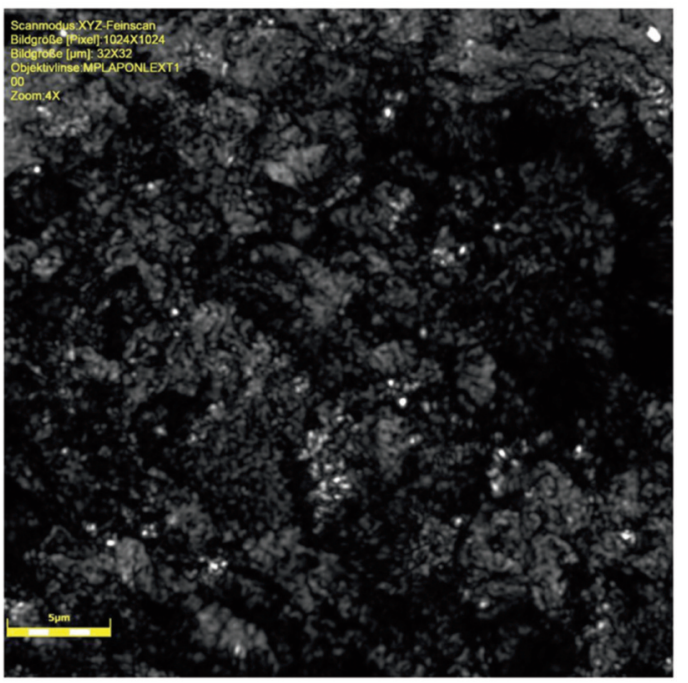

H

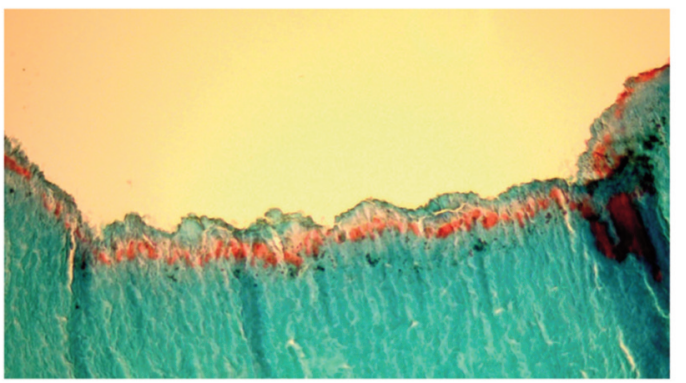

Figure 1. Continued 


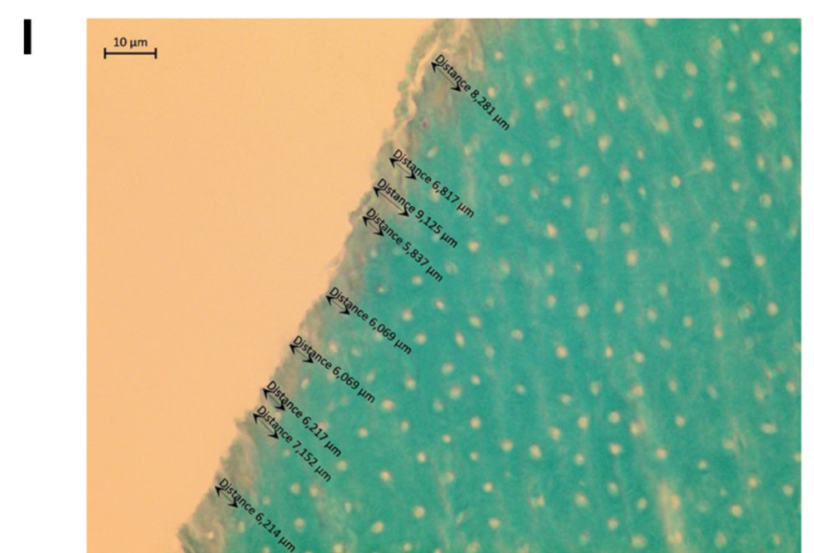

K

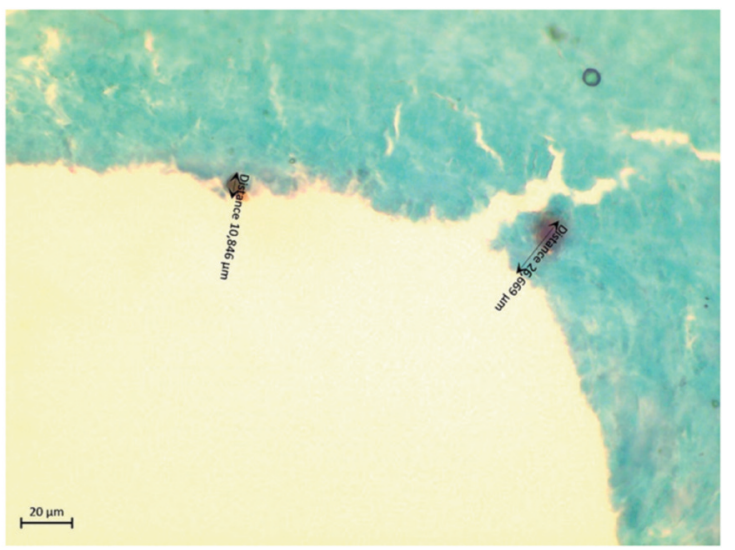

M

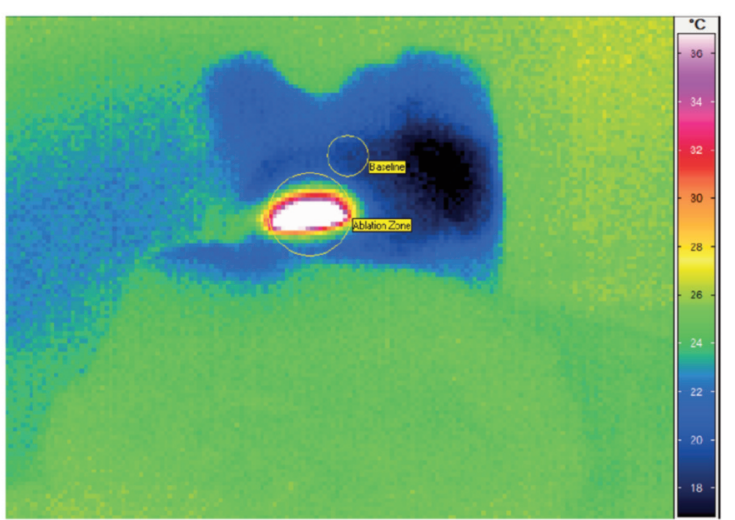

$\mathbf{J}$

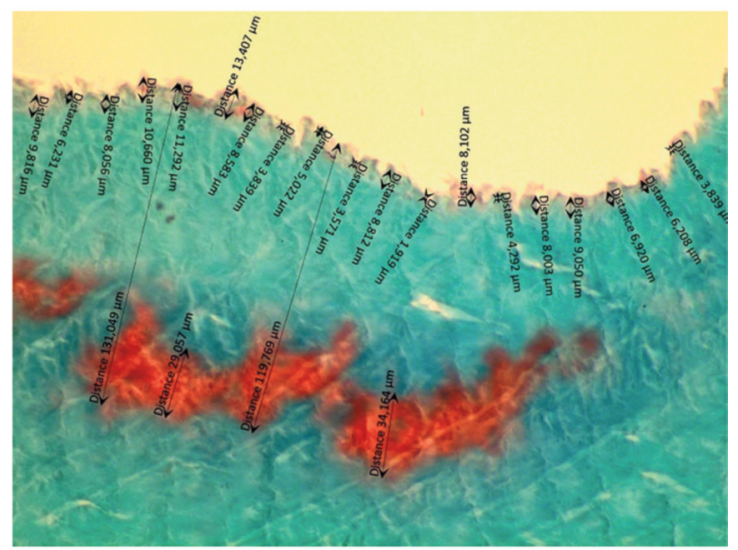

$\mathbf{L}$

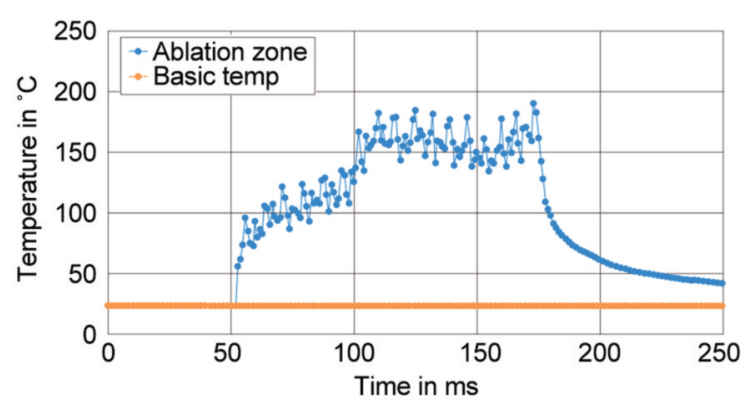

$\mathbf{N}$

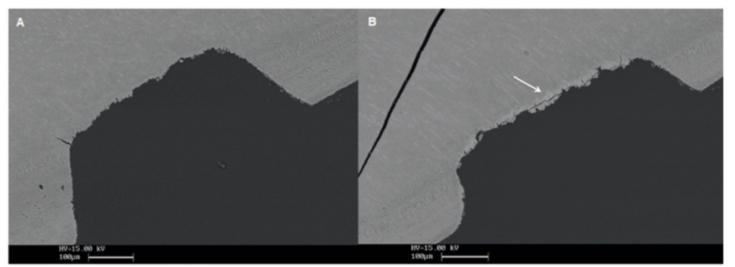

Figure 1. Overview of ablation of the tooth root by the picosecond infrared laser (PIRL). (A) Photograph of PIRL induced dentin ablation. No. 1-4 indicate four sites of laser application with increased ablation depths according to ascending number. Grooved cutting bottoms are visible (Tooth No. 2.3). (B) Detail of the root of tooth 2.3 is shown in Figure 1A. Stage 1 ablation shows parallel grooves of focused tissue ablation, original magnification 30x (Tooth 2.3). (C) Thermal effect on dentin following laser ablation (arrow). (D) Tooth 2.2 cutting edge of incision No. 4 . Smooth cutting edge and even ablation base. $1.1 \times$ zoom. Bar indicates $100 \mu \mathrm{m}$. (E) Serrated surface of ablation edge. The dark holes correspond to opened dentin tubules. $1 \times$ zoom (Tooth 7.2, section 1). Bar indicates $50 \mu \mathrm{m}$. (F) Hilly rugged preparation base at higher magnification. $4 \times$ zoom (Tooth 7.2, section 1). Bar indicates 5 um. (G) Converging cavity to the base of the preparation, tooth No. 2.1, section 4, 20 scans (Original magnification 25x). (H) Wavy cutting base of tooth, 5 scans (Tooth No. 3.1, section 1, original magnification 100x). Note the plaster-like and line-shaped, red marked dentin layer below the preparation base. (I) Example for measurement of gray areas covering the cutting base (Tooth No. 6.1). Bar indicates $10 \mu \mathrm{m} .(\mathrm{J})$ Dentin morphometrics defining the laser ablation zone. A thin gray area is covering the cavity. Red areas are located deeper within the dentin and are distinct from the surface of the cavity. Red areas on the cutting base were defined as thermal damage (Tooth No. 1.2 section 4). (K) Laser ablation of dentin in a zone without any morphological equivalent to thermal damage. There are no gray areas on the cutting bottom (Tooth No. 2.3, section 2). Bar indicates $20 \mu \mathrm{m}$. (L) Thermal imaging camera monitoring of heat developing during laser application (Tooth 4.3; sec $3=$ section 3, ms=millisecond). (M) Measurement of heat development on the processed object. Note the considerable drop in temperature outside of focus. (N) Scanning electron microscopic photograph of ablation zones of tooth No. 7.1 (left=section 1, right=section 2). The white arrow (section 2) points on the white border visible by light microscopy at the cutting edge, 150x magnification (Bar indicates $100 \mu \mathrm{m}$ ). 
using Masson-Goldner staining. These findings were assessed as thermal mineralization defects (Figure 1I). The gray areas were distributed along the entire length of the sections. In some places, Masson-Goldner trichrome staining showed sharply defined, homogeneous red colored spots in dentin below the cutting surface. At certain points, the condensed particles lay directly on the surface of the ablation. However, in some cases, the cuts were without any red staining. These findings were not evaluated as direct thermal damage to dentin, but as areas with altered mineralization or mineral loss through denaturation (Figure $1 \mathrm{~J})$. Some sections did not show any structural alterations on the bottom surface cut out by PIRL. This staining result was registered as an area without detectable thermal effects of PIRL on the hard tissue (Figure 1K).

Infrared camera. The heat measurement showed different, but very significant increases in the temperature of the processed object (Figure $1 \mathrm{~L}$ and $1 \mathrm{M}$ ). A maximum temperature of up to $189.9^{\circ} \mathrm{C}$ was measured on tooth No. 4.3 (section 3 ) during the ablation procedure. The temperature drop outside the beam focus was significant. The temperature fell below $40^{\circ} \mathrm{C}$ within the processed root.

SEM. Sections 1, 2, 3 and 5 of tooth No. 7.1 were included in the statistic evaluation. The figures (1D-1E) show the cross sectioned tooth with individual laser cuts. The respective cutting numbers are marked in the picture. Laser cuts of different depths are presented. Here, the conical cutting edges can also be easily recognized, which become more conical by increasing the scans per cut (cut 5 shows the most scans). According to histological evaluation, sections 2 and 3 showed higher thermal penetration depths compared to sections 1 and 5. If the incisions are viewed at a higher magnification (Figure $1 \mathrm{~N}$ ), it can be seen that on average the deeper-acting thermal damage correlated positively with increased conicity of the depth of the cut. The white fringe on the bottom of the cut is evaluated as thermal damage (arrow in Figure 1N). The whitish lines are running lengthwise into the depth below the section floor. These lines morphologically correlate to incised dentin. Furthermore, the corrugated and jagged, conical tapered cavity bottoms were covered by sprinkled tissue sections.

Statistical evaluation of thermal effects. The mean value of thermal effect with respect to the damaged zone in the dentin at 5 scans per laser cut was $15.18 \mu \mathrm{m}$, with 10 scans the mean value was $10.87 \mu \mathrm{m}$ and 20 scans per laser cut was $10.92 \mu \mathrm{m}$. Standard deviation and median are shown in Table II. A slightly higher mean value of the thermal effects with 5 scans is noticeable. Thermal effects to the tooth structures occurred to the same extent at all laser cutting depths. There was no significant deviation from the average values $(p<0.529)$.
Table II. Mean value of thermal damage in $\mu m$.

\begin{tabular}{lcrccc}
\hline $\begin{array}{l}\text { Number } \\
\text { of cutting } \\
\text { sections }\end{array}$ & Mean & Median & $\begin{array}{l}\text { Standard } \\
\text { deviation }\end{array}$ & Minimum & Maximum \\
\hline 5 & 15.18 & 17.03 & 12.96 & 0.00 & 34.23 \\
10 & 10.87 & 9.70 & 3.88 & 6.39 & 20.08 \\
20 & 10.92 & 8.79 & 7.59 & 6.50 & 30.71 \\
\hline
\end{tabular}

\section{Discussion}

In this study, PIRL was successfully tested for cutting precision at the roots of 10 teeth. In addition, it became evident that significant temperature development is measurable during the ablation of the hard tissue. The partial ablation of the tooth root was performed as an initial apicoectomy with incisions of different depths, which were aligned horizontally and parallel to each other. The results show that PIRL is in principle suitable for this procedure. Cutting precision was comparable to that of other systems, e.g. removal with a drill (39-48). However, there were deviations from rectangular ablation of dentin at the processed ground, insofar as here the tissue removal became a conical transition. However, the cutting precision was excellent, as evidenced by the fact that the $\mathrm{z}$-shaped pattern of the ablation path was reflected in the relief of the bottom of the cavity. Considerable heat development occurred during the application of the PIRL regardless of the depth of penetration of the laser beam. Hyperthermic effects are evident when using PIRL in tissues with relatively low water. Faster scanning speeds to prevent thermal accumulation may mitigate this problem. It became clear in the investigations that thermal effects occur during dentin treatment with PIRL, which require careful cooling of the processed hard tissue for clinical use. In contrast to this finding, Franjic et al. (2009) in pilot-studies on PIRL used no cooling for surface treatment of tooth enamel (7). The examinations were limited to preparations within the acellular component of the tooth. The distribution of energy resulted in a highly efficient ablation of enamel. However, the defects after focal application of PIRL showed irregularities of the crater shape. In scanned ablation of enamel, grooved ablation margins were visible in the wall and bottom of the cavity in SEM (7). Similar ablation rates were achieved with superficial treatment of enamel with a $\mathrm{CO}_{2}$ laser. The temperature increases with and without cooling were no greater than about $3^{\circ} \mathrm{C}$ (49). However, such superficial incisions are far away from the clinical situation of root resection, where deep tissue treatment is required (50). Heat generation during laser ablation depends on the type of dental hard tissue (enamel or dentin) and the thickness of the respective tissue (51). 
However, lasers generated greater heat increase of the dental pulp in an in vitro study on thermal effects of ablating instruments $(50,52)$. Nevertheless, heat generation during process was below the $5.5^{\circ} \mathrm{C}$ threshold margin of safety in all experiments $(50,52)$.

Visual and light-microscopical aspects of cavity. Examination of the boundaries of the laser cut in tooth roots with the naked eye and under low magnification reveals a clearly defined ablation of the hard tissue which accurately traces the movement of the laser beam. The transition from the root surface to the cavity is formed at right angles. The transition of the vertical ablation zone to the bottom of the cavity is slightly conical in shape.

In the microscopic assessment, the comparison of the cutting precision and surface deformation by a diamond drill with that of the PIRL shows no notable differences (53). In the study of Ruckenstuhl (53), among other details, the surface of the dentin machined with a diamond bur was examined. The dentin surface machined with a drill resembles the ribbed cutting bottom of the laser cut in this study. For comparison, the wavy feature of the laser cut bottom surface was particularly well visible in Figure $1 \mathrm{H}$. The pattern was generated by the given path of the laser scan over the processed surface. The z-shaped running pattern of the laser beam leads to the visible unevenness of the cavity floor. In a comparable laser study, dentin was cut and examined in a similar way using a nanosecond pulsed $\mathrm{Cr}$ :CdSe laser. Thermal penetration depth was $14.2 \pm 0.7 \mu \mathrm{m}$ at a wavelength of $\lambda=2.9 \mu \mathrm{m}$ (46). The results of Lin et al. (46) are similar to the results of the present study. However, thermal effects to the hard tissues were subjectively measured on the histological specimens (46). The reproducibility of the measurements of thermal effects by subjective estimates is likely inferior to the morphometric analysis of specifically stained sections as chosen here.

SEM. SEM shows that PIRL does not leave the cutting surface evenly but rather wavy in structure. The laser parameters such as the pulse spacing and the path of the laser also play a role. Comparing the cross sections of dentin ablations using SEM and light micrsocopy published in studies with similar experimental settings (46), it is noticeable that the cavity ground of the referred study shows similar patterns to PIRL preparations, except that the ablation bottom was not wavy. However, this fact is due to the experimental conditions, because in Lin et al.'s study, the laser ablated a line or a point and not an adjusted surface, so that the trajectory of the laser could not leave a pattern on the cutting bottom (46). The cutting precision is similar to that of other laser systems (46) or diamond drills, so that it appears to be suitable for dental use in terms of its cutting precision.
Comparison of dental root preparation with osteotomies by PIRL. The teeth have a natural curvature and so it is possible that areas of the ablation surface were not at the height of the adjusted focus when starting the ablation. Energy transfer is not optimal at the surface of the root, so insufficiently fast laser scanning can cause focal overheating of the object leading to visible burn stripes or even areal (Figure 1M). However, temperature increases were also found in deeper layers of the preparation, where a straight root surface had been produced by the ablations of the laser. Comparing the images of a recent study on PIRL osteotomy (9), obtained with an environmental scanning microscopy (ENSEM), with the images of LEXT, which were obtained in the present study, it is noticeable that dental ablations in this study have more resemblance to the intersection of the Erbium-YAG laser of the study published by Jowett et al. (2014) than to osteotomy surfaces provided by PIRL. The difference may be due to the higher ablation rates and faster scanning speeds for bone. Furthermore, fresh, unfixed bone was also processed in this study (9). Presumably, formalin crosslinking can render PIRL ablation less efficient.

Dentin consists of an organic and an inorganic portion. More than $90 \%$ of the organic fraction consists of collagen and about $8-9 \%$ of non-collagenous ground substance. The collagen is almost exclusively Type I, with less than $3 \%$ type $\mathrm{V}$ collagen. The mineral content of dentin (hydroxyapatite) contains calcium and phosphate in the equilibrium ratio of about $1: 2.1$. The crystals are about 3-4 $\mathrm{nm}$ wide and 60-70 $\mathrm{nm}$ long (54). The physical properties of dental hard tissue differ from one layer to another and are anisotropic as well as inhomogeneous in each layer, even for a single tooth (55). Both the composition of inorganic ingredients as well as those of collagen vary in different dentin layers, e.g. mantle dentin, peritubular dentin and dentin close to the pulp chamber $(54,56)$. Thus, micro-morphological differences are present during the preparation of this hard tissue, that only at first glance appears to be a homogeneous material. The differences in dentin composition may have an impact on the laser's ablation quality. That's why it can be assumed that PIRL achieves different incision results on dental hard tissue than on bone due to the differences in material characteristics. Compared to the SEM images (similar magnification as LEXT) of the study by Lin et al. (46), it is noticeable that the cavity edge of the sections with the PIRL appears much smoother and more even than the cutting edges with the $\mathrm{Cr}$ :CdSe laser. Compared to other lasers or ablation instruments, the cutting precision is therefore at least equivalent to the diamond drill $(53,57)$ and better than that of the Cr: CdSe laser.

Temperature generation during laser ablation. PIRL causes selective excitation of water's vibrational modes that couple directly to translation modes of the water molecules to provide 
the driving for ablation of the tissue. This energy transmission results in superheating on picoseconds timescales. The nucleation sites for the ablative phase transition have nanometer dimensions, avoiding cavitation and associated shock wave induced damage of surrounding structures (6). The technical characteristics of PIRL ensure that all the absorbed photon energy ablates tissue on time scales much faster than heat transfer can damage adjacent tissue of the targeted area (6). However, the ablation performance of PIRL is highly dependent on the water content of the tissue. Dentin has a water content less than bone $(10 \%$ vs. $20 \%)(58,59)$. Indeed, laser-induced cutting of the tooth root takes much longer than a focal surface engraving in enamel (7) or dentin $(36,48)$ or superficial cavity preparation $(60)$, so that considerable thermal effects can accumulate during application of the laser to achieve certain cutting depths, provided that the local cooling does not reach the work surface. On the other hand, the high energy density is desirable in the removal of dental hard tissue because thermal effects become more pronounced with decreasing energy and longer pulse duration of laser (61). Teeth can compensate for acute temperature differences within certain limits without permanent damage to the enamel or dentin (62). Body temperature may be sufficient for some laser applications for sufficient cooling (63), but is apparently not enough to process hard tissue without damage (15). The maximum temperatures reached in the application lead to the melting of dentin (64).

Water spray cooling is an essential part in both laser and standard dental bur drilling of hard tissue and enamel in order to reduce temperature effects $(35,65,66)$. A rise of $7^{\circ} \mathrm{C}$ has been considered a limit of the biologically acceptable increase in temperature at the root surface. High temperature increase leads to the irreversible destruction of oral soft tissue $(43,65)$. Heat generation during laser procedures on teeth may result in carbonization, melting, and cracking of tooth structures $(2,67)$. For example, thermal denaturation of dentin collagen is possible during endodontic treatments (68), where the tooth root canal dentin may be exposed to a temperature higher than $100^{\circ} \mathrm{C}(64)$. Thermal conductivity of human dentin increases with increasing volume fraction of dentin tubules (69). However, increase in pulse number does not cause secondary effects such as thermal and mechanical damage in the cavities of hard tissues (70). In contrast, other studies show that high repetition rates lead to high thermal and mechanical damage after femtosecond laser application. The hydration state of the teeth had a significant impact on the ablation properties of the laser (71). Constant addition of fine water mist directly at the ablation side very likely will neither substantially decrease the ablation nor cause carbonization and melting in the surrounding dental hard and soft tissue (72). This effect is largely due to the water ablation of the externally supplied cooling water that contributes to cutting by cavitation which offsets the decrease in the amount of laser energy deposited in the tooth.
The comparison of heat generation during PIRL osteotomy of bone and dental root ablation reveals important differences. In the osteotomy study, the temperature on the surface of the ablation zone increased by an average of $1.56^{\circ} \mathrm{C}$ during laser ablation, whereas in our experiment the temperature increased by more than 10 times. This difference in heat generation on Celsius scale can in part be attributed to differences in material characteristics. In fact, dentin contains only about $50 \%$ of the water content of bones. However, methodological differences between both studies may be explain better this result than differences in water content. During PIRL osteotomy, continuous spray water cooling was used, allowing continuous lowering of temperature during the scan (15). Irrigation of the cut surface was reported to be necessary when using femtosecond laser for osteotomy. This step takes time and affects the visibility of the field of use (27). A femtosecond laser created skull defects that resulted in slightly delayed bone healing during the observation period ( 3 to 12 weeks) when compared with mechanical drilling. However, the difference was not statistically significant. The authors concluded that this type of laser was suitable for bone removal and that bone healing following laser osteotomy had little difference from a standard procedure (27). However, the skull of the mouse is much thinner than a human tooth root. Registration of the laser-induced change in object temperature during use is recommended in order to compare technical effects with biological consequences (36). In the present study, intermittent water cooling was provided only during scans. This application of cooling agent was a compromise between the published apparently athermal ablation of enamel with PIRL and our experience of carbonization margins during ablation of dentin in our own investigations. Thus, water cooling apparently was insufficient to ensure the same relatively small increase in temperature as in osteotomy. However, when planning the treatment of dental hard tissues, Franjic et al. (7) concluded that the processing of enamel by PIRL has been possible without measurable temperature increase. The water spray effectively cooled the teeth; while using the maximum average power investigated $(10 \mathrm{~Hz}, 360$ $\mathrm{mJ} /$ pulse), a water flow rate of $4.5 \mathrm{ml} / \mathrm{min}$ limited the temperature rise in the pulp chamber to less than $3^{\circ} \mathrm{C}(73)$. The water spray minimally reduced the ablation rates of dentin and did not affect the ablation rates of enamel (73), but this minor effect on material processing has to be proven for PIRL in treatment of dentin. There is also significant difference in the repetition rate of PIRL $(1 \mathrm{KHz})$ relative to $10 \mathrm{~Hz}$ in the aforementioned study. This difference makes it difficult to scan fast enough to avoid accumulating heat effects. The much lower pulse energy of PIRL requires faster scanning to offset the difference in cutting rates. This problem will be resolved once higher pulse energy PIRL systems or scanning systems are available. 
Expected developments. Presently, heat development on the surface of the dental root ablation area without permanent cooling is clearly too high for clinical application. A suitable water irrigation, water spray or air-cooling system must be found and tested in further studies. Furthermore, the cutting parameters, such as the pulse spacing or the trajectory of the laser beam on a surface should be adapted and tested again to improve the quality of the cutting surface. It is to be expected that a modified run-off sheet, which is specially tested for hard tissue, will be able to make the surface texture of the cavity's floor much smoother. If these parameters are further tested and improved in terms of shape cutting, PIRL should be a much more promising laser than previous models on the market.

In this study, the ablation depth was evaluated as a result of the preselected laser scans. It has recently been pointed out that the theoretically expected ablation of dentin does not correspond to the actual ablation (74). With elaborate experimental approaches, especially adjusting the timing of increments along the focal plane during the ablation of the dentin, the ablation error could be controlled (74).

By using different laser repetition rates with intermittent application of thin layers of water, cooling performance could be improved to mitigate accumulation of excess heat and associated deleterious thermal effects. Automated correction techniques may reduce heat build-up during incision and further improve the laser's cutting precision of the hard tissue (46). In fact, experimental, automated bone laser osteotomies have been successfully performed in which a constant osteotomy depth has been achieved (Er:YAG laser) (47). Measurement results on temperature development during osteotomy have not been reported (47). All these device improvements target a robotic-assisted or navigated application of the ablation instruments (47). In the in vitro setting, the tooth surface and laser beam could be optimally aligned with each other. However, the targeted application of the laser beam can be difficult in the apicoectomy of molars in the clinical setting. There is currently no routine clinical application of robotic assisted surgery in this application. In clinical use with hand-held applicator, a flexible applicator is the prerequisite for apicoectomy. Current developments of a flexible applicator should take this clinical requirement into account (75). Initial results have shown that multimode fiber can provide lossless energy transfer of PIRL to difficult-toreach objects (76).

\section{Conclusion}

The mode of action of PIRL allows a nearly athermic dissociation at the subcellular level in soft tissues. When used in teeth, thermal effects occur, which are probably caused by the low water content of the organ and smaller ablation volumes that lead to less heat removed from the ablated zone. Faster scanning with higher power PIRLs may solve this problem. The demand for a constant cooling during the PIRL application in clinical settings with the present PIRL technology is indispensable for the treatment of dentin. Nevertheless, the precision of the cuts in dentin is excellent and offers an alternative to other instruments for the treatment of dental hard tissues.

\section{Conflicts of Interest}

RJDM is the author of the patent covering the PIRL process and is one of the founders of Attodyne Inc., Toronto, Canada. All other Authors declare no conflicts of interest. There has been no financial relationship with any sponsoring organization.

\section{Authors' Contributions}

Design of study and carrying out the experiments: MQ, REF, NJ, PK. Histological investigations of specimens: MA, JZ, MQ, REF. Design and construction of the laser: PK, WW, RJDM. Draft manuscript: REF, MQ, FKK, HS, RJDM. All Authors gave their final approval to submit the manuscript for publication.

\section{Acknowledgements}

This study is part of the SUREPIRL project funded by an advanced grant of the European Research Council (ERC-AdG-2011-291630). The Authors appreciate the help in the statistical evaluation of data provided by the colleagues of the Institute for Medical Biometry and Epidemiology at the University Hospital Hamburg-Eppendorf. The Authors thank Dr. Wolfgang Wöllmer, Department of Otorhinolaryngology, Eppendorf University Hospital, for the support in the laser experiments and to Dr. Kresimir Franjic, Toronto, Canada, for helpful discussions during the initial phase of this research.

\section{References}

1 Keller U and Hibst R: Zur ablativen Wirkung des Er:YAG Lasers auf Schmelz und Dentin. Dtsch Zahnärztl Zeitschr 44: 600-602, 1989.

2 Wigdor HA, Walsh JT jr, Featherstone JD, Visuri SR, Fried D and Waldvogel JL: Lasers in dentistry. Lasers Surg Med 16: 103133, 1995. PMID: 7769957. DOI: 10.1002/lsm.1900160202

3 Deppe $\mathrm{H}$ and Horch $\mathrm{HH}$ : Laser applications in oral surgery and implant dentistry. Lasers Med Sci 22: 217-221, 2007. PMID: 17268764. DOI: $10.1007 / \mathrm{s} 10103-007-0440-3$

4 Deppe $\mathrm{H}$, Horch $\mathrm{HH}$ and Neff A: Conventional versus $\mathrm{CO} 2$ laser-assisted treatment of peri-implant defects with the concomitant use of pure-phase beta-tricalcium phosphate: a 5year clinical report. Int J Oral Maxillofac Implants 22: 79-86, 2007. PMID: 17340900 .

5 Thomson PJ, Goodson ML, Cocks $\mathrm{K}$ and Turner JE: Interventional laser surgery for oral potentially malignant disorders: a longitudinal patient cohort study. Int J Oral Maxillofac Surg 46: 337-342, 2017. PMID: 27866683. DOI: 10.1016/j.ijom.2016.11.001

6 Amini-Nik S, Kraemer D, Cowan ML, Gunaratne K, Nadesan P, Alman BA and Miller RJ: Ultrafast mid-IR laser scalpel: protein 
signals of the fundamental limits to minimally invasive surgery. PLoS One 5(9): pii: e13053, 2010. PMID: 20927391. DOI: 10.1371/journal.pone. 0013053

7 Franjic K, Cowan ML, Kraemer D and Miller RJ: Laser selective cutting of biological tissues by impulsive heat deposition through ultrafast vibrational excitations. Opt Express 17: 22937-22959, 2009. PMID: 20052221. DOI: 10.1364/OE. 17.022937

8 Franjic $\mathrm{K}$ and Miller D: Vibrationally excited ultrafast thermodynamic phase transitions at the water/air interface. Phys Chem Chem Phys 12: 5225-5239, 2010. PMID: 20431828. DOI: $10.1039 / \mathrm{c} 000359 \mathrm{j}$

9 Jowett N, Wöllmer W, Mlynarek AM, Wiseman P, Segal B, Franjic K, Krötz P, Böttcher A, Knecht R and Miller RJ: Heat generation during ablation of porcine skin with erbium:YAG laser $v s$. a novel picosecond infrared laser. JAMA Otolaryngol Head Neck Surg 139: 828-833, 2013. PMID: 23949359. DOI: 10.1001/jamaoto.2013.3974

10 Freedman JR, Kaufman J, Metelitsa AI and Green JB: Picosecond lasers: the next generation of short-pulsed lasers. Semin Cutan Med Surg 33: 164-168, 2014. PMID: 25830248. DOI: $10.12788 /$ j.sder.0117

11 Kwiatkowski M, Wurlitzer M, Omidi M, Ren L, Kruber S, Nimer R, Robertson WD, Horst A, Miller RJ and Schlüter H: Ultrafast extraction of proteins from tissues using desorption by impulsive vibrational excitation. Angew Chem Int Ed Engl 54: 285-288, 2015. PMID: 25346525. DOI: 10.1002/anie.201407669

12 Ren L, Robertson WD, Reimer R, Heinze C, Schneider C, Eggert D, Truschow P, Hansen NO, Kroetz P, Zou J and Miller RJ: Towards instantaneous cellular level bio diagnosis: laser extraction and imaging of biological entities with conserved integrity and activity. Nanotechnology 26: 284001, 2015. PMID: 26111866. DOI: $10.1088 / 0957-4484 / 26 / 28 / 284001$

13 Petersen H, Tavakoli F, Kruber S, Münscher A, Gliese A, Hansen NO, Uschold S, Eggert D, Robertson WD, Gosau T, Sehner S, Kwiatkowski M, Schlüter H, Schumacher U, Knecht $\mathrm{R}$ and Miller RJ: Comparative study of wound healing in rat skin following incision with a novel picosecond infrared laser (PIRL) and different surgical modalities. Lasers Surg Med 48: 385-391, 2016. PMID: 26941063. DOI: $10.1002 / \mathrm{lsm} .22498$

14 Hess M, Hildebrandt MD, Müller F, Kruber S, Kroetz P, Schumacher U, Reimer R, Kammal M, Püschel K, Wöllmer W and Miller D: Picosecond infrared laser (PIRL): an ideal phonomicrosurgical laser? Eur Arch Otorhinolaryngol 270: 2927-2937, 2013. PMID: 23708442. DOI: 10.1007/s00405-0132561-6

15 Jowett N, Wöllmer W, Reimer R, Zustin J, Schumacher U, Wiseman PW, Mlynarek AM, Böttcher A, Dalchow CV, Lörincz BB, Knecht R and Miller RJ: Bone ablation without thermal or acoustic mechanical injury via a novel picosecond infrared laser (PIRL). Otolaryngol Head Neck Surg 150: 385-393, 2014. PMID: 24376121. DOI: 10.1177/0194599813517213

16 Böttcher A, Kucher S, Knecht R, Jowett N, Krötz P, Reimer R, Schumacher U, Anders S, Münscher A, Dalchow CV, Miller RJD: Reduction of thermocoagulative injury via use of a picosecond infrared laser (PIRL) in laryngeal tissues. Eur Arch Otorhinolaryngol 272: 941-948, 2015. PMID: 25575843. DOI: 10.1007/s00405-015-3501-4

17 Linke SJ, Frings A, Ren L, Gomolka A, Schumacher U, Reimer R, Hansen NO, Jowett N, Richard G and Miller RJ: A new technology for applanation free corneal trephination: the picosecond infrared laser (PIRL). PLoS One 10: e0120944, 2015. PMID: 25781907. DOI: 10.1371/journal.pone.0120944

18 Mehlan J, Uschold S, Hansen NO, Gosau T, Eggert D, Spitzer M, Petersen H, Linke SJ and Miller RJD: [Picosecond infrared laser fiber-assisted sclerostomy (PIRL-FAST): A first proof of principle analysis]. Ophthalmologe 116: 346-350, 2019. PMID: 29387935. DOI: 10.1007/s00347-018-0653-9

19 Rodrigo JP, Suárez C, Silver CE, Rinaldo A, Ambrosch P, Fagan JJ, Genden EM and Ferlito A: Transoral laser surgery for supraglottic cancer. Head Neck 30: 658-666, 2008. PMID: 18327778. DOI: 10.1002/hed.20811

20 Jerjes W, Hamdoon Z and Hopper C: CO2 lasers in the management of potentially malignant and malignant oral disorders. Head Neck Oncol 4: 17, 2012. PMID: 22546534. DOI: $10.1186 / 1758-3284-4-17$

21 Jaeger F, Chiavaioli GM, de Toledo GL, Freire-Maia B, Amaral MBF and Mesquita RA: High-power diode laser in the circumvestibular incision for Le Fort I osteotomy in orthognathic surgery: a prospective case series study. Lasers Med Sci 33: 5156, 2018. PMID: 28951983. DOI: 10.1007/s10103-017-2333-4

22 Thomson PJ, Goodson ML and Smith DR: Potentially malignant disorders revisited-The lichenoid lesion/proliferative verrucous leukoplakia conundrum. J Oral Pathol Med 47: 557-565, 2018. PMID: 29663518. DOI: 10.1111/jop.12716

23 Strauss RA and Fallon SD: Lasers in contemporary oral and maxillofacial surgery. Dent Clin North Am 48: 861-888, vi, 2004. PMID: 15464556. DOI: 10.1016/j.cden.2004.06.005

24 Horch $\mathrm{HH}$ and Keiditsch E: Morphologische Befunde über die Gewebeschädigung und Knochenregeneration nach LaserOsteotomie. Dtsch Zahnarztl Z 35: 22-24, 1980.

25 Horch HH: Laser-Osteotomie und Anwendungsmöglichkeiten des Lasers in der oralen Weichteilchirurgie. Eine tierexperimentelle und klinische Studie. Quintessenz, Berlin, 1983.

26 Spencer P, Payne JM, Cobb CM, Reinisch L, Peavy GM, Drummer DD, Suchman DL and Swafford JR: Effective laser ablation of bone based on the absorption characteristics of water and proteins. J Periodontol 70: 68-74, 1999. PMID: 10052773. DOI: 10.1902/jop.1999.70.1.68

27 Cloutier M, Girard B, Peel SA, Wilson D, Sándor GK, Clokie $\mathrm{CM}$ and Miller D: Calvarial bone wound healing: a comparison between carbide and diamond drills, Er:YAG and Femtosecond lasers with or without BMP-7. Oral Surg Oral Med Oral Pathol Oral Radiol Endod 110: 720-728, 2010. PMID: 20656526. DOI: 10.1016/j.tripleo.2010.04.003

28 Friedrich G, Dikkers FG, Arens C, Remacle M, Hess M, Giovanni A, Duflo S, Hantzakos A, Bachy V and Gugatschka M; European Laryngological Society, Phonosurgery Committee: Vocal fold scars: current concepts and future directions. Consensus report of the Phonosurgery Committee of the European Laryngological Society. Eur Arch Otorhinolaryngol 270: 2491-507, 2013. PMID: 23605306. DOI: 10.1007/s00405013-2498-9

29 von Arx T, Peñarrocha $M$ and Jensen S: Prognostic factors in apical surgery with root-end filling: A meta-analysis. J Endod 36: 957-973, 2010. PMID: 20478447. DOI: 10.1016/j.joen. 2010.02 .026

30 Jacobsen T, Norlund A, Sandborgh-Englund G and Tranæus S: Application of laser technology for removal of caries: A systematic review of controlled clinical trials. Acta Odont Scand 
69: 65-74, 2011. PMID: 21319941. DOI: 10.3109/00016357. 2010.536901

31 Mogedas-Vegara A, Hueto-Madrid JA, Chimenos-Küstner E and Bescós-Atín C: Oral leukoplakia treatment with the carbon dioxide laser: A systematic review of the literature. J Craniomaxillofac Surg 44: 331-336, 2016. PMID: 26920045. DOI: $10.1016 /$ j.jcms.2016.01.026

32 Smaïl-Faugeron V, Glenny AM, Courson F, Durieux P, MullerBolla $\mathrm{M}$ and Fron Chabouis H: Pulp treatment for extensive decay in primary teeth. Cochrane Database Syst Rev 5: CD003220, 2018. PMID: 29852056. DOI: 10.1002/14651858. CD003220.pub3

33 Grgurević J, Grgurević L, Miletić I, Karlović Z, Krmek SJ and Anić I: In vitro study of the variable square pulse Er:YAG laser cutting efficacy for apicectomy. Lasers Surg Med 36: 347-350, 2005. PMID: 15856510 . DOI: $10.1002 / \mathrm{lsm} .20168$

34 Del Fabbro M, Corbella S, Sequeira-Byron P, Tsesis I, Rosen E, Lolato A and Taschieri S: Endodontic procedures for retreatment of periapical lesions. Cochrane Database Syst Rev 10: CD005511, 2016. PMID: 27759881. DOI: 10.1002/14651858. CD005511.pub3

35 Bodrumlu E, Keskiner I, Sumer M, Sumer AP and Telcıglu NT: Temperature variation during apicectomy with Er:YAG laser. Photomed Laser Surg 30: 425-428, 2012. PMID: 22730914. DOI: 10.1089 /pho.2012.3256

36 Domke M, Wick S, Laible M, Rapp S, Huber HP and Sroka R: Ultrafast dynamics of hard tissue ablation using femtosecondlasers. J Biophotonics 11: e201700373, 2018. PMID: 29845754. DOI: $10.1002 /$ jbio.201700373

37 Burkhardt R: Präparative Voraussetzungen zur klinischen Histologie des menschlichen Knochenmarks. Blut 13: 337-357 and 14: 30-46, 1966. DOI: 10.1007/BF01633515

38 Nowak I: Die knöcherne Einheilung von Zirkon- und Titanimplantaten - Eine histologische und ultrastrukturelle Untersuchung, Medical Dissertation, University of Düsseldorf, 2010.

39 Stern RH and Sognnaes RF: Laser effect on dental hard tissues. A preliminary report. J South Calif State Dent Assoc 33: 17-19, 1965. PMID: 14241171.

40 Stern RH, Vahl J and Sognnaes RF: Lased enamel: ultrastructural observations of pulsed carbon dioxide laser effects. J Dent Res 51: 455-460, 1972. PMID: 4551319. DOI: $10.1177 / 00220345720510023501$

41 Miserendino LJ: The laser apicoectomy: endodontic application of the $\mathrm{CO}_{2}$ laser for periapical surgery. Oral Surg Oral Med Oral Pathol 66: 615-619, 1988. PMID: 3143988. DOI: 10.1016/00304220(88)90385-4

42 Moritz A, Gutknecht N, Goharkhay K, Schoop U, Wernisch J, Pöhn C and Sperr W: The carbon dioxide laser as an aid in apicoectomy: an in vitro study. J Clin Laser Med Surg 15: 185188, 1997. PMID: 9612168. DOI: 10.1089/clm.1997.15.185

43 Nammour S, Kowaly K, Powell GL, Van Reck J and Rocca JP: External temperature during KTP-Nd:YAG laser irradiation in root canals: an in vitro study. Lasers Med Sci 9: 27-32, 2004. PMID: 15278724. DOI: 10.1007/s10103-004-0303-0

44 Nomelini SM, Souza-Gabriel AE, Marchesan MA, Sousa-Neto MD and Silva-Sousa YT: Ultrastructural analysis of radicular dentine surface submitted to $\mathrm{CO} 2$ laser at different parameters. Microsc Res Tech 72: 737-743, 2009. PMID: 19378343. DOI: 10.1002/jemt.20723
45 Lustosa-Pereira AC, Pozza DH, Cunha A, Dedavid BA, Duartede Moraes JF and Gerhardt-de Oliveira M: Analysis of the morphology and composition of tooth apices apicectomized using three different ablation techniques. Med Oral Patol Oral Cir Bucal 16: e225-e230, 2011. PMID: 20711132. DOI: 10.4317/ medoral.16.e225

46 Lin M, Xu F, Lu TJ and Bai BF: A review of heat transfer in human tooth--experimental characterization and mathematical modeling. Dent Mater 26: 501-513, 2010. PMID: 20303579. DOI: $10.1016 /$ j.dental.2010.02.009

47 Augello M, Deibel W, Nuss K, Cattin P and Jürgens P: Comparative microstructural analysis of bone osteotomies after cutting by computer-assisted robot-guided laser osteotome and piezoelectric osteotome: an in vivo animal study. Lasers Med Sci 33: 1471-1478, 2018. PMID: 29654421. DOI: 10.1007/s10103018-2502-0

48 Petrov T, Pecheva E, Walmsley AD and Dimov S: Femtosecond laser ablation of dentin and enamel for fast and more precise dental cavity preparation. Mater Sci Eng C Mater Biol Appl 90: 433-438, 2018. PMID: 29853109. DOI: 10.1016/j.msec. 2018.04.070

49 Staninec M, Darling CL, Goodis HE, Pierre D, Cox DP, Fan K, Larson M, Parisi R, Hsu D, Manesh SK, Ho C, Hosseini M and Fried D: Pulpal effects of enamel ablation with a microsecond pulsed lambda=9.3-microm CO2 laser. Lasers Surg Med 41: 256-263, 2009. PMID: 19347946. DOI: 10.1002/lsm.20748

50 Penn C, Beninati C, Mariano A, Dooley D, Harsono M, Perry R and Kugel G: Thermal effects on pulp due to laser and handpiece usage. Compend Contin Educ Dent 35: e41-e44, 2014. PMID: 25454819.

51 Braun A, Krillke RF, Frentzen M, Bourauel C, Stark H and Schelle F: Heat generation caused by ablation of dental hard tissues with an ultrashort pulse laser (USPL) system. Lasers Med Sci 30: 475-481, 2015. PMID: 23666547. DOI: 10.1007/s10103013-1344-z

52 Kilinc E, Roshkind DM, Antonson SA, Antonson DE, Hardigan PC, Siegel SC and Thomas JW: Thermal safety of Er:YAG and Er,Cr:YSGG lasers in hard tissue removal. Photomed Laser Surg 27: 565-570, 2009. PMID: 19694507. DOI: 10.1089/pho.2008.2335

53 Ruckenstuhl M: Der Einfluss unterschiedlicher Präparationsmethoden auf die Klebehaftung von Keramikwerkstücken am Zahnschmelz, Medical Dissertation, University of Graz, 2014.

54 Schroeder HE: Orale Strukturbiologie. Georg Thieme Verlag, Stuttgart, 1992, pp. 114-118.

55 Marshall GW jr.: Dentin: microstructure and characterization. Quintessence Int 24: 606-617, 1993. PMID: 8272499.

56 Craig RG, Gehring PE and Peyton FA: Relation of structure to microhardness of human dentin. J Dent Res 38: 624-630, 1959. PMID: 13654615. DOI: 10.1177/00220345590380032701

57 Pistorius A, Platte G and Willershausen B: Zum Einfluss von rotierendem Präparationsinstrumentarium auf die Oberflächenbeschaffenheit von humanem Zahnschmelz. Dtsch Zahnärztl Zeitschr 61: 183-187, 2006.

58 Smillie AC: The chemistry of the organic phase of teeth. In: Zipkin I: Biological Mineralization, Wiley, New York, 1973, pp. 139.

59 Jones IL and Leaver AG: Studies on the minor components of the organic matrix of human dentine. Arch Oral Biol 19: 371-380, 1974. PMID: 4369238. DOI: 10.1016/0003-9969(74)90178-2 
60 Freitas PM, Navarro RS, Barros JA and de Paula Eduardo C: The use of Er:YAG laser for cavity preparation: an SEM evaluation. Microsc Res Tech 70: 803-808, 2007. PMID: 17576132. DOI: $10.1002 /$ jemt.20470

61 Anić I, Dzubur A, Vidović D and Tudja M: Temperature and surface changes of dentine and cementum induced by $\mathrm{CO} 2$ laser exposure. Int Endod J 26: 284-293, 1993. PMID: 8300260. DOI: 10.1111/j.1365-2591.1993.tb00573.x

62 Baldissara P, Catapano S and Scotti R: Clinical and histological evaluation of thermal injury thresholds in human teeth: a preliminary study. J Oral Rehabil 24: 791-801, 1997. PMID: 9426160. DOI: 10.1046/j.1365-2842.1997.00566.x

63 Valente NA, Calascibetta A, Patianna G, Mang T, Hatton M and Andreana S: Thermodynamic effects of 3 different diode lasers on an implant-bone interface: An ex vivo study with review of the literature. J Oral Implantol 43: 94-99, 2017. PMID: 28001482. DOI: 10.1563/aaid-joi-D-16-00188

64 Armstrong SR, Jessop JL, Winn E, Tay FR and Pashley DH: Effects of polar solvents and adhesive resin on the denaturation temperatures of demineralised dentine matrices. J Dent 36: 8-14, 2008. PMID: 18022750. DOI: 10.1016/j.jdent.2007.10.003

65 Machida T, Wilder-Smith P, Arrastia AM, Liaw LH and Berns MW: Root canal preparation using the second harmonic KTP:YAG laser: a thermographic and scanning electron microscopic study. J Endod 21: 88-91, 1995. PMID: 7714444. DOI: $10.1016 /$ S0099-2399(06)81102-7

66 Pashley DH: Dynamics of the pulpo-dentin complex. Crit Rev Oral Biol Med 7: 104-133, 1996. PMID: 8875027. DOI: $10.1177 / 10454411960070020101$

67 Chiang YC, Lee BS, Wang YL, Cheng YA, Chen YL, Shiau JS, Wang D and Lin CP: Microstructural changes of enamel, dentinenamel junction, and dentin induced by irradiating outer enamel surfaces with CO2 laser. Lasers Med Sci 23: 41-48, 2008. PMID: 17384974. DOI: 10.1007/s10103-007-0453-y

68 Kaitsas V, Signore A, Fonzi L, Benedicenti S and Barone M: Effects of Nd: YAG laser irradiation on the root canal wall dentin of human teeth: a SEM study. Bull Group Int Rech Sci Stomatol Odontol 43: 87-92, 2001. PMID: 11938590.

69 Figueiredo de Magalhães M, Neto Ferreira RA, Grossi PA and de Andrade RM: Measurement of thermophysical properties of human dentin: effect of open porosity. J Dent 36: 588-594, 2008. PMID: 18547708. DOI: 10.1016/j.jdent.2008.04.006
70 Nicolodelli G, Lizarelli Rde F and Bagnato VS: Influence of effective number of pulses on the morphological structure of teeth and bovine femur after femtosecond laser ablation. J Biomed Opt 7: 048001, 2012. PMID: 22559697. DOI: 10.1117/ 1.JBO.17.4.048001

71 Rego Filho Fde A, Dutra-Corrêa M, Nicolodelli G, Bagnato VS and de Araujo MT: Influence of the hydration state on the ultrashort laser ablation of dental hard tissues. Lasers Med Sci 28: 215-222, 2013. PMID: 22585381. DOI: 10.1007/s10103$012-1118-\mathrm{Z}$

72 Hossain M, Nakamura Y, Yamada Y, Kimura Y, Nakamura G and Matsumoto K: Ablation depths and morphological changes in human enamel and dentin after Er:YAG laser irradiation with or without water mist. J Clin Laser Med Surg 17: 105-109, 1999. PMID: 11199828. DOI: 10.1089/clm.1999.17.105

73 Visuri SR, Walsh JT jr and Wigdor HA: Erbium laser ablation of dental hard tissue: effect of water cooling. Lasers Surg Med 18: 294-300, 1996. PMID: 8778525. DOI: 10.1002/(SICI)10969101(1996)18:3<294:AID-LSM11>3.0.CO;2-6

74 Sun Y, Yuan F, Lv P, Wang D, Wang L and Wang Y: Method to control depth error when ablating human dentin with numerically controlled picosecond laser: a preliminary study. Lasers Med Sci 30: 1435-1441, 2015. PMID: 24890033. DOI: 10.1007/s10103-014-1596-2

75 Maier S: Studies of laser ablation, biodiagnostics, and new laser surgery applications under conditions of ultrafast desorption by impulsive vibrational excitation (DIVE). Dissertation, Faculty of Physics, University of Hamburg, 2017: Available at: http://ediss.sub.uni-hamburg.de/volltexte/2018/9293/ [Last accessed May 28, 2020]

76 Petersen H, Gliese A, Stober Y, Maier S, Hansen NO, Kruber S, Eggert D, Tóth M, Gosau T, Schlüter H, Püschel K, Schumacher U, Miller RJD, Münscher A and Dalchow C: Picosecond infrared laser (PIRL) application in stapes surgery-First experience in human temporal bones. Otol Neurotol 39: e224-e230, 2018. PMID: 29533330. DOI: 10.1097/MAO.0000000000001753 